Covered in: Web of Sciences (WOS); EBSCO; ERIH+; Google Scholar; Index Copernicus; Ideas RePeC; Econpapers; Socionet; CEEOL; Ulrich ProQuest; Cabell, Journalseek; Scipio; Philpapers; SHERPA/RoMEO repositories; KVK; WorldCat; CrossRef; CrossCheck

2018, Volume 10, Issue 1, pages: 62-70 | doi: https://doi.org/10.18662/rrem/18

\section{Futsal Player Rehabilitation after Anterior Cruciate Ligament (ACL) \\ Reconstruction}

\section{Cosmin DAMIAN ${ }^{1}$, Mirela DAMIAN $*^{2}$}

\begin{abstract}
${ }^{1} \mathrm{Ph} . \mathrm{D}$. Candidate, Faculty of Physical Education and Sport, Ovidius University of Constanta, Romania, e-mail address: cosmin.damian@yahoo.com
\end{abstract} ${ }^{2}$ Prof. Ph.D., Faculty of Physical Education and Sport, Ovidius University of Constanta, Romania, mireladamian13@gmail.com

\section{Corresponding author}

Abstract: Anterior cruciate ligament (ACL) tears are one of the most common knee injuries in sports. This research provide a scientific basis for the rehabilitation protocol after anterior cruciate ligament (ACL) reconstruction and present a subject experiences in the rehabilitation process after surgery, using futsal specific exercises with the purpose of returning in 6 months to sport activity. The subject which was tested is 18-years-old male, futsal player with anterior cruciate ligament (ACL) reconstruction with a hamstrings autograft. The rehabilitation protocol spans over a 6 month period and was divided into 4 phases [table 1], for a total of about 288 sessions. The rehabilitation protocol it started a 7 day after surgery, at a rate of 2 sessions a day, 6 days a week The goals and exercise for each phase involve: range of motion (ROM), flexibility, normalizing gait, activation of the quadriceps muscle, strength and endurance, proprioception, cardiovascular fitness, specific technical and tactical futsal skills. The criteria for each phase progression were evaluated with Lower Extremity Functional Scale (LEFS). This study case suggests a high rehabilitation after ACL reconstruction, the key elements in the rehabilitation program is specificity goal and exercises of futsal game, performed in a individual and team training. Organizing the rehabilitation protocol with addressability and specificity of futsal exercises is necessary to speed up recovery.

Keywords: ACL, surgery, futsal, rehabilitation.

How to cite: Damian, C., \& Damian, M. (2018). Futsal Player Rehabilitation after Anterior Cruciate Ligament (ACL) Reconstruction. Revista Romaneasca pentru Educatie Multidimensionala, 10(1), 62-70. https://doi.org/10.18662/rrem/18 


\section{Introduction}

In futsal game, the players repeatedly produce maximal or sub maximal actions, turning, sprinting, pivoting of short duration with brief recovery periods. These actions predispose the players to injuries. The anterior cruciate ligament (ACL) is the most commonly injury in highperformance athletes. Return to sports after ACL reconstruction is a big challenge for both, the athlete and the physical therapist (Teodor, 2017). A carefully planned rehabilitation program that addresses all aspects of the game is vital to return the player to maximum function, while minimizing risk of reinjury (Bizzini, Hancock, \& Franco Impellizzeri, 2012). The management of patients after anterior cruciate ligament reconstruction should be evidence based (Adams, Logerstedt, \& Hunter-Giordano, 2012).

\section{Problem Statement}

Van Hespen et al., found that Dutch First League futsal players reveal 38\% knee ligaments injuries (Van Hespen, Stege, \& Stubbe, 2011). The reconstruction surgery after ACL rupture is necessary to help the athletes to return to their sports career. The surgery is necessary to maximize the knee stability and functional capacity. Arden et al., claim that surgery helps the athletes to return to preinjury activity levels and sports participation (L., Webster, \& Taylor, 2011). Pre-surgery rehabilitation with graded physiotherapy programme results in improved postoperative recovery, reduced pain, swelling, better stability and improved range of motion (Van Grinsven, Van Cingel, Holla, \& Van Loon, 2010). Return to sports after ACL reconstruction is a big challenge for both the athlete and the physical therapist (Teodor, 2017). For the athletes who want to return to sport, the rehabilitation program must continue until this is possible (Rambaud et al., 2017). To consider an ACL reconstruction successful, the patient should be able to return to the same level of sporting activity as before the injury (Lynch et al., 2015). The rehabilitation and return to sport after ACL reconstruction is influenced by physical, psychological and contextual factors. The decision to allow an athlete to return to sport should be based, first of all, on a series of intrinsic factors, that depend exclusively on the patient himself, such as genetics, lesion type, anatomical features, rehabilitation protocols, motivation, psychological attitude and extrinsic factors type of graft, surgical technique, rehabilitation phases, biological support (Zaffagnini, Grassi, Serra, \& Marccaci, 2015). The current rehabilitation programs after ACL reconstruction are more aggressive than 
those used in the past, the athlete wanting to return to normal sports as fast as possible. Knowledge of healing processes and biomechanics in the knee joint after injury and reconstruction, together with physiological aspects on training effects is important for the construction of rehabilitation programmes (Kvist, 2004). The literature offers mainly anecdotal evidence to guide the team physician in the decision-making process, with a paucity of criteria and consensus guidelines available to help determine return to sport (Everhart, Best, \& Flanigan, 2015) . In my opinion a close cooperation between the patient, physiotherapist, surgeon, coach and family athlete is necessary. Education and communication are vital in managing expectations and progressing through a protocol safely and successfully (Malempati et al., 2015).

In their updated review, Ardern et al., showed that, on average, $80 \%$ of patients returned to sport, while only $55 \%$ returned to competitive levels after ACL reconstruction (C. L. Ardern, Taylor, \& Feller, 2014).

The psychological factors play an important role in recovery after ACL reconstruction, the fear of reinjury being the most commonly cited reason among athletes for not returning to sport (C.L. Ardern, Webster, Taylor, \& Feller, 2011; Teodor, 2017). After injury and during recovery stage, the athletes present negative emotional attitude, including shock, frustration, tension, or anger (Morrey, Stuart, Smith, \& M., 1999), (Walker, Thatcher, \& Lavallee, 2007).

Ardern, et al., say that psychological readiness to return to sport (measured with the ACL-RSI scale) was the factor most strongly associated with returning to the preinjury sport or recreational activity after ACL reconstruction (C. L. Ardern, Osterberg, \& Tagesson, 2014). Optimism, confidence, motivation, self-efficacy, and lower fear of a new injury are the psychological factors that have been associated with the likelihood of returning to the preinjury level following ACL reconstruction (Czuppon, Racette, \& Klein, 2013), (Ellman, 2015; Everhart et al., 2015). The recovery and return to sport after ACL reconstruction depends on contextual factors which can influence the maximization of rehabilitation programs. Arden et al. (2014) promote most of the contextual factors identified as impacting on returning to sport are non-modifiable, for example, gender, age and preinjury sports participation level (C. L. Ardern et al., 2014). For athletes to return to competition, they must regain muscular strength and neuromuscular control in their injured leg while maintaining static stability (Teodor, 2017). 


\section{Research Questions/Aims of the research}

The aim of this research was to provide a scientific basis for the rehabilitation protocol after anterior cruciate ligament (ACL) reconstruction. It also intended to organize a rehabilitation protocol using futsal specific exercises with the purpose of returning in 6 months to the same level of sport activity as before the injury.

\section{Research Methods}

This research is based on a study case. The subject which was tested is 18-years-old male, futsal player in a national league, with anterior cruciate ligament (ACL) reconstruction. The rehabilitation protocol it started a 7 day after surgery, at a rate of 2 sessions a day, 6 days a week, to the Idu Club. The rehabilitation protocol spans over a 6 month period and was divided into 4 phases [table1], for a total of about 288 sessions. The time that was allocated to each session varied between 60 and 90 minutes. The player was followed and evaluated for the 6 months, to ensure that he returns to the same level of sports before the injury. The goals and exercise suggestions for each phase involve: range of motion (ROM) and flexibility, normalizing gait and activation of the quadriceps muscle, strength and endurance, proprioception, cardiovascular fitness, specific technical and tactical futsal skills (individual and team training). The criteria for each phase progression were evaluated with Lower Extremity Functional Scale (LEFS) (Stratford et al., 2005). The questionnaire consists of 20 items, each scored on a scale of 0 to 4 . Total scores vary from 0 to 80 points, with higher values representing better rehabilitation and functional status. A clinically important change has occurred if the score changes 9 or more scale points from a previous score (Stratford et al., 2005). In each phase of the subject protocol, the LEFS scores are presented (Table 1). Frequency and intensity of rehabilitation sessions are important. One of the key elements in a soccer-specific rehabilitation program is an understanding of the physical demands of the sport and the level of play to which the player needs to return (Bizzini et al., 2012). 


\section{Findings}

\subsection{Tables}

Table1 Phases of Rehabilitation

\begin{tabular}{|c|c|c|c|c|}
\hline Timing & $\begin{array}{c}\text { Phase } 1 \\
\text { weeks 0-2 }\end{array}$ & $\begin{array}{c}\text { Phase } 2 \\
\text { weeks3-6 }\end{array}$ & $\begin{array}{c}\text { Phase } 3 \\
\text { Weeks7-16 }\end{array}$ & $\begin{array}{c}\text { Phase } 4 \\
\text { weeks17-24 }\end{array}$ \\
\hline Goals & $\begin{array}{l}\text { Reducing edema and } \\
\text { pain; } \\
\text { Normalize walking; } \\
\text { Increase range of } \\
\text { motion (ROM); } \\
\text { Improve flexibility; } \\
\text { Full extension and } \\
\text { partial flexion of } 90^{\circ} \text {; } \\
\text { Quadriceps activation, } \\
\text { voluntary contractions; } \\
\text { Balance re-education; } \\
\text { Maintain } \\
\text { cardiovascular fitness; } \\
\text { Maintain normal } \\
\text { weight; }\end{array}$ & $\begin{array}{l}\text { Improve range of } \\
\text { motion (ROM); } \\
\text { Improve flexibility; } \\
\text { Full extension and } \\
\text { almost full flexion; } \\
\text { Improve quadriceps } \\
\text { strength muscle } \\
\text { Improve } \\
\text { proprioception, } \\
\text { knee stabilization; } \\
\text { Prepare basic futsal } \\
\text { specific } \\
\text { neuromuscular control; } \\
\text { Improve cardiovascular } \\
\text { fitness; } \\
\text { Maintain normal } \\
\text { weight; }\end{array}$ & $\begin{array}{l}\text { Improve range of } \\
\text { motion (ROM); } \\
\text { Improve flexibility; } \\
\text { Full extension and } \\
\text { full flexion; } \\
\text { Improve all strength } \\
\text { muscle: } \\
\text { Improve knee } \\
\text { stabilization; } \\
\text { Optimize futsal } \\
\text { specific } \\
\text { neuromuscular } \\
\text { control; } \\
\text { Prepare the player for } \\
\text { return to team } \\
\text { practice; } \\
\text { Improve } \\
\text { cardiovascular fitness; }\end{array}$ & $\begin{array}{l}\text { Prepare the player for } \\
\text { competitive futsal; } \\
\text { Improve specific } \\
\text { neuromuscular control } \\
\text { Improve futsal } \\
\text { skills:speed agility, } \\
\text { coordination strength; } \\
\text { Improve conditioning: } \\
\text { good Yo-Yotest results; } \\
\text { Optimize plyometrics } \\
\text { training; Equal range of } \\
\text { motion (ROM); } \\
\text { Return to full futsal } \\
\text { practice; Individual and } \\
\text { team soccer exercises }\end{array}$ \\
\hline Exercises & $\begin{array}{l}\text { Simple } \\
\text { exercises(ROM): } \\
\text { Flexion } 4 \times 20 \\
\text { Extension } 4 \times 20 \\
\text { Adduction } 4 \times 20 \\
\text { Abduction 4x20 } \\
\text { Voluntary cvadriceps } \\
\text { contractions; 4x30 } \\
\text { Patellar mobilizations; } \\
\text { Walking 3x15. Core } \\
\text { body strength } 5 \text { min. }\end{array}$ & $\begin{array}{l}\text { Endurance training: } \\
\text { bike, }(2 \times 3 \text { min } 50 \% \\
\text { heart rate); stepper level } \\
5 . \\
\text { TheraBand } \\
\text { exercises } 4 \times 15 \\
\text { Proprioception and } \\
\text { static balance exercises } \\
10 \text { min } \\
\text { Bosu balance: Semi- } \\
\text { squads, } 5 x \text { p: } 15 \text { sec. [ } \\
\text { (Damian \& Popa, 2015) } \\
\text { Wobble board } 3 \times \\
30 \text { sec. }\end{array}$ & $\begin{array}{l}\text { Endurance training: } \\
\text { bike, running }(3 \mathrm{x} 4 \\
\text { min } 60 \% \text { heart rate); } \\
\text { Agility drills: lateral, } \\
\text { diagonal, } \\
\text { forward; } 4 \times 4,6,8,12 \mathrm{~m} \\
\text { Running: specific } \\
\text { futsal exercises } \\
\text { without the ball } 10 \\
\text { min. Pool crawl } \\
\text { swimming. }\end{array}$ & $\begin{array}{l}\text { Pliometrics exercises } \\
\text { are scheduled after } \\
\text { heating (Negrea, } \\
\text { Negrea, \& Teodor, } \\
\text { 2010) Agility drills: } \\
\text { lateral, diagonal, } \\
\text { forward, zigzag; } \\
\text { 6x4,6,8,12 m. Passing: } \\
\text { short distances, } \\
\text { dribbling; Yo-Yo test; } \\
\text { Running: specific futsal } \\
\text { exercises with the ball; } \\
\text { Tactical skills }\end{array}$ \\
\hline
\end{tabular}

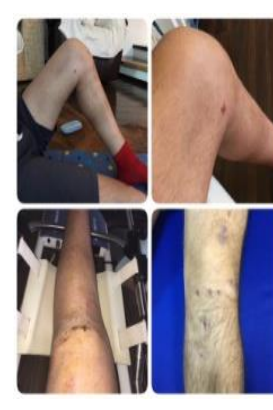
$30 \mathrm{sec}$
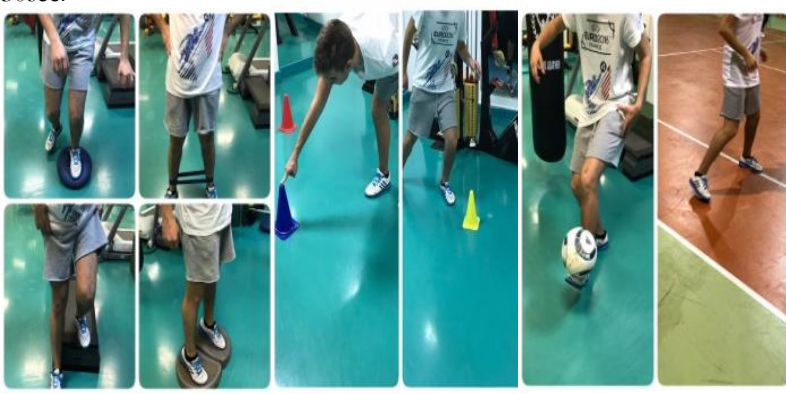


\section{Discussions}

This study case suggests a high rehabilitation after ACL reconstruction to a futsal player. This athlete underwent arthroscopically assisted ACL reconstruction with a hamstrings autograft and after 6 months returned to competitive level. The athlete rehabilitation presented here followed without complications, he showed a strong psychological determination to return to play. The progressive training program allowed the patient to play first futsal game in 144 days after surgery. The literature studies show, that the results for return to the same level of sports post-ACL reconstruction are varied. Most recent studies claim a 4-9 months (Harner, Fu, Irrgang, \& Vogrin, 2001), (Howell \& Hull, 1998), (Shelbourne \& Nitz, 1990), (Sherman, Lieber, Bonamo, Podesta, \& Reiter, 1991), (Fabbriciani, Milano, Mulas, Ziranu, \& Severini, 2005), (Zaffagnini et al., 2014).

In the first phase (week 0-1) the score of Lower Extremity Functional Scale (LEFS) was 16 points. After (ROM) exercises, quadriceps voluntary contractions and patellar mobilizations, the score increased to 21 points. In the week 1-2 after introducing the walking exercises and core body strength, the score was 28 points.

In the second phase (week 3-4), following the same exercises as in the first stage, the Lower Extremity Functional Scale (LEFS) score was 34 points. After introducing the bike exercises and elliptical machine, the score increased to 43. In the week 5-6 after introducing the TheraBand exercises; Proprioception and static balance exercises: Bosu balance, Wobble board; the score was 50 points.

In the third phase (week 7-11), following the same exercises as in the second stage but slightly increasing the intensity, the Lower Extremity Functional Scale (LEFS) score was 54 points. Agility can be improved with agility training drills but also by improving the specific individual fitness elements of speed, balance, power and co-ordination (Teodor 2018). After introducing the agility drills exercises, the score increased to 61 points.

In the week 12-16, after introducing the running and specific futsal exercises without the ball, the score was 64 points.

In the fourth phase (week 17-20), following the same exercises as in the third stage, the Lower Extremity Functional Scale (LEFS) score was 68 points. In the week 21-23, after introducing specific futsal exercises with the ball and Yo-Yo test; the score increased to 77 points. The score changes more 9 points from a previous score, which shows an important progress in the functional status. The innovation of the rehabilitation protocol is 
represented of futsal specific exercises with the ball, performed in a individual and team training.

\section{Conclusions}

This study case suggests a high rehabilitation after ACL reconstruction, the key elements in the rehabilitation program is specificity goal and exercises of futsal game, performed in a individual and team training. After 6 months of training, the total score of Lower Extremity Functional Scale (LEFS) was 77 points, which means that the athlete can return to his sporting activity in normal conditions without the risk of reinjury. Organizing the rehabilitation protocol with addressability and specificity of futsal exercises is necessary to speed up recovery. Returning to sport without a complete and specific recovery involves major risks for the athlete: injury to the meniscus, cartilage or increase the risk of reinjury. In organizing the rehabilitation protocol, close cooperation between the futsal player, physiotherapist, surgeon, coach and family athlete is necessary.

\section{References}

Adams, D., Logerstedt, D., \& Hunter-Giordano, A. (2012). Current concepts for anterior cruciate ligament reconstruction: a criterionbased rehabilitation progression. Journal of Orthopaedic \& Sports Physical Therapy, 601-614.

Ardern, C. L., Osterberg, A., \& Tagesson, S. (2014). The impact of psychological readiness to return to sport and recreational activities after anterior cruciate ligament reconstruction. British Journal of Sports Medicine, 1613-1619.

Ardern, C. L., Taylor, N. F., \& Feller, J. A. (2014). Fifty-five per cent return to competitive sport following anterior cruciate ligament reconstruction surgery: an updated systematic review and metaanalysis including aspects of physical functioning and contextual factors. British Journal of Sports Medicine, 48, 1543-1552.

Ardern, C. L., Webster, K. E., Taylor, N. F., \& Feller, J. A. (2011). Return to sport following anterior cruciate ligament reconstruction surgery: a systematic review and meta-analysis of the state of play. Br J Sports Med, 45(7), 596-606. doi:https://doi.org/10.1136/bjsm.2010.076364

Bizzini, M., Hancock, D., \& Franco Impellizzeri, F. (2012). Suggestions From the Field for Return to Sports Participation Following Anterior Cruciate Ligament Reconstruction. Soccer, Journal of 
Orthopaedic \& Sports Physical Therapy,, 42(4), 304-312. doi:10.2519/jospt.2012.4005

Czuppon, S., Racette, B. A., \& Klein, S. E. (2013). Variables associated with return to sport following anterior cruciate ligament reconstruction: A systematic review. British Journal of Sports Medicine, 356-364.

Damian, M., \& Popa, C. (2015). Bosu exercices for improvement of balance to children whit down syndrom. GYMNASIUM. Scientific Journal of Education, Sports and Health, 1 Supplement (16).

Ellman, M. B. (2015). Return to play following anterior cruciate ligament reconstruction. Journal of $A A O S, 23(5)$.

Everhart, J. S., Best, T. M., \& Flanigan, D. C. (2015). Psychological predictors of anterior cruciate ligament reconstruction outcomes: A systematic review. Knee Surgery, Sports Traumatology, Arthroscopy, 23, 752-762.

Fabbriciani, C., Milano, G., Mulas, P. D., Ziranu, F., \& Severini, G. (2005). Anterior cruciate ligament reconstruction with doubled semitendinosus and gracilis tendon graft in rugby players. Knee Surgery, Sports Traumatology, Arthroscopy, 13.

Harner, C. D., Fu, F., Irrgang, J. J., \& Vogrin, T. M. (2001). Anterior and posterior cruciate ligament reconstruction in the new millennium: a global perspective. . Knee Surgery, Sports Traumatology, Arthroscopy, 9, 330-336.

Howell, S. M., \& Hull, M. L. (1998). Aggressive rehabilitation using hamstring tendons: graft construct, tibial tunnel placement, fixation properties, and clinical outcome. The American Journal of Knee Surgery, 120-127.

Kvist, J. (2004). Rehabilitation following anterior cruciate ligament injury: current recommendations for sports participation. Sports Medicine, 34, 269-280.

Lynch, A. D., Logerstedt, D. S., Grindem, H., Eitzen, I., Hicks, G. E., Axe, M. J., ... Snyder-Mackle, r. L. (2015). Consensus criteria for defining successful outcome' after ACL injury and reconstruction: a Delaware-Oslo ACL cohort investigation. British Journal of Sports Medicine, 49(5), 335342.

Malempati, C., Jurjans, J., Noehren, P. T., Ireland, M. D., Darren, L., \& Johnson, M. D. (2015). Current Rehabilitation Concepts for Anterior Cruciate Ligament Surgery in Athletes. Orthopedics, 38 (11).

Morrey, M. A., Stuart, M. J., Smith, A. M., \& M., W.-B. D. (1999). A longitudinal examination of athletes' emotional and cognitive 
responses to anterior cruciate ligament injury. Clinical Journal of Sport Medicine: Official Journal of the Canadian Academy of Sport Medicine.

Negrea, V., Negrea, M., \& Teodor, D. (2010). Influence of physical training pliometrics exercises the fifth grade. Series Physical Education and Sport/Science, Movement and Health, 10 (2 Supplement).

Rambaud, A. J. M., Semay, B., Samozino, P., Morin, J. B., Testa, R., Philippot, R., . . . Edouard, P. (2017). Criteria for Return to Sport after Anterior Cruciate Ligament reconstruction with lower reinjury risk (CR'STAL study): protocol for a prospective observational study in France. BMJ Open, 7 (6).

Shelbourne, K. D., \& Nitz, P. (1990). Accelerated rehabilitation after anterior cruciate ligament reconstruction.

The American Journal of Sports Medicine, 292-299.

Sherman, M. F., Lieber, L., Bonamo, J. R., Podesta, L., \& Reiter, I. (1991). The long-term followup of primary anterior cruciate ligament repair. Defining a rationale for augmentation. The American Journal of Sports Medicine, 19, 243-255.

Stratford, P. W., Hart, D. L., Binkley, J. M., Kennedy, D. M., Alcock, G. K., \& Hanna, S. E. (2005). Physiotherapy. Interpreting lower extremity functional status scores. Physiotherapy Canada, 57(2).

Teodor, D. F. (2017). When return to sport athletes after the anterior cruciate ligament (ACL) injury? . Science, Movement and Health, 17(2 Supllement ), 517-522.

Teodor D. F. (2018). Physical conditioning -speed and agility in youth football. Science, Movement and Health, XVIII(1), 2018 January 2018, 18 (1): $80-84$

Van Grinsven, S., Van Cingel, R. E., Holla, C. J., \& Van Loon, C. J. (2010). Evidence-based rehabilitation following anterior cruciate ligament reconstruction. Sports Traumatology Arthroscopy.

Van Hespen, A., Stege, J. P., \& Stubbe, J. H. (2011). Soccer and futsal injuries in the Netherlands. British Journal of Sports Medicine, 45(4).

Walker, N., Thatcher, J., \& Lavallee, D. (2007). Psychological responses to injury in competitive sport. The Journal of the Royal Society for the Promotion of Health, 127(174-180).

Zaffagnini, S., Grassi, A., Marcheggiani, M., G. M., Tsapralis, K., Ricci, M., Bragonzoni, L., . . . Marcacci, M. K. (2014). Return to sport after anterior cruciate ligament reconstruction in professional soccer players. Knee, 21(3). 
Futsal Player Rehabilitation after Anterior Cruciate Ligament (ACL) ... Cosmin DAMIAN, Mirela DAMIAN

Zaffagnini, S., Grassi, A., Serra, M., \& Marccaci, M. (2015). Return to sport after ACL reconstruction: how, when and why? A narrative review of current evidence. Joints, 3(1). 